Research Paper

\title{
Chemoprevention of Low-Molecular-Weight Citrus Pectin (LCP) in Gastrointestinal Cancer Cells
}

\author{
Shi Wang ${ }^{1,2}$, Pei $\mathrm{Li}^{3}$, Sheng-Min Lu ${ }^{4}$ Zhi-Qiang Ling ${ }^{凶}$ \\ 1. Zhejiang Cancer Research Institute, Zhejiang Province Cancer Hospital, Zhejiang Cancer Center, No.38 Guangji Rd., Banshanqiao District, Hangzhou \\ 310022, P.R.China. \\ 2. Department of Digestive Endoscopy, Zhejiang Province Cancer Hospital, Zhejiang Cancer Center, No.38 Guangji Rd., Banshanqiao District, Hangzhou \\ 310022, P.R.China. \\ 3. Department of Pathophysiology, School of Basic Medical Sciences, Zhengzhou University, Zhengzhou, 450052, China. \\ 4. Institute of Food Science, Zhejiang Academy of Agriculture Science, No. 298 Desheng Rd., Hangzhou 310021, P.R.China.
}

$\triangle$ Corresponding author: Zhi-Qiang Ling, M.D, Ph.D., Zhejiang Cancer Research Institute, Zhejiang Province Cancer Hospital, Zhejiang Cancer Center, No.38 Guangji Rd., Banshanqiao District, Hangzhou 310022, China. Tel: +86-571-88122423, Fax: +86-571-88122587 E-mail: lingzq@zjcc.org.cn or lingzq@hotmail.com.

(1) Ivyspring International Publisher. Reproduction is permitted for personal, noncommercial use, provided that the article is in whole, unmodified, and properly cited. See http://ivyspring.com/terms for terms and conditions.

Received: 2015.09.28; Accepted: 2016.02.25; Published: 2016.04.28

\begin{abstract}
Background \& Aims: Low-molecular-weight citrus pectin (LCP) is a complex polysaccharide that displays abundant galactosyl (i.e., sugar carbohydrate) residues. In this study, we evaluated the anti-tumor properties of LCP that lead to Bcl-xL -mediated dampening of apoptosis in gastrointestinal cancer cells.

Methods: We used AGS gastric cancer and SW-480 colorectal cancer cells to elucidate the effects of LCP on cell viability, cell cycle and apoptosis in cultured cells and tumor xenografts.

Results: Significantly decreased cell viabilities were observed in LCP treated AGS and SW-480 cells $(P<0.05)$. Cell cycle-related protein expression, such as Cyclin B1, was also decreased in LCP treated groups as compared to the untreated group. The AGS or SW-480 cell-line tumor xenografts were significantly smaller in the LCP treated group as compared the untreated group $(P<0.05)$. LCP treatment decreased Galectin-3 (GAL-3) expression levels, which is an important gene in cancer metastasis that results in reversion of the epithelial-mesenchymal transition (EMT), and increased suppression of $\mathrm{Bcl}-\mathrm{xL}$ and Survivin to promote apoptosis. Moreover, results demonstrated synergistic tumor suppressor activity of LCP and 5-FU against gastrointestinal cancer cells both in vivo and in vitro.

Conclusions: LCP effectively inhibits the growth and metastasis of gastrointestinal cancer cells, and does so in part by down-regulating Bcl-xL and Cyclin B to promote apoptosis, and suppress EMT. Thus, LCP alone or in combination with other treatments has a high potential as a novel therapeutic strategy to improve the clinical therapy of gastrointestinal cancer.
\end{abstract}

Key words: Low-molecular-weight citrus pectin (LCP); gastrointestinal cancer cells; caspases; apoptosis; epithelial- mesenchymal transition (EMT).

\section{Introduction}

Gastrointestinal cancer is an important malignant tumor and a significant threat to human health [1]. Even with remarkable gains in our understanding of the molecular mechanisms that are involved in the most common gastrointestinal cancers, it is obvious that the most promising hope in the foreseeable future lies in the chemoprevention strategies of recurrent cancer and its associated precursors. Experimental, epidemiological, and clinical data from the past two decades have each supported the hypothesis that some chemopreventive agents possesses anti-cancer properties, and that use of chemopreventive approaches might also reduce the lifetime probability of developing or dying from a variety of cancers [2-5]. The most convincing evidence supports the notion that a plant-based diet that is rich 
in both fruits and vegetables, is protective, and connotes decreased risk for gastrointestinal cancer [6-8]. Many experimental chemopreventive agents have been derived from plant chemistry of foods that are associated with a decreased risk of developing cancers of the gastrointestinal tract [6-10]. Among the agents currently in experimental studies and clinical testing are anti-oxidants [11], metabolic modulators [12], epigenetic modulators [13], anti-proliferatives [14], anti-angiogenic [15], and reversion of epithelialmesenchymal transition (EMT) [16], among other approaches that are beyond the scope if this article. The present status of ongoing gastrointestinal cancer prevention trials suggests that this disease, in particular, may well be clinically suited to chemopreventive approaches. An increasing number of novel technologies have been used as to assess the mechanism and efficacy of particular preventive strategies.

Citrus pectin, a natural substance which was found in pulp and peel of citrus fruits like tangerines, grapefruits, lemons and oranges, is a complex polysaccharide containing abundant galactosyl (sugar carbohydrate) residues $[17,18]$. Low-molecularweight citrus pectin (or LCP) used in this current study consists of short, slightly-branched, carbohydrate chains which come from the soluble albedo fraction of citrus fruit peels, and these chains are modified to decrease molecular weight and degree of esterification through physical and biological methods including temperature, $\mathrm{pH}$, and enzymatic process, thus we increased its absorption into the circulatory system. LCP is relatively rich in galactose, and it can antagonize a binding protein known as Galectin-3 (GAL-3), leanding to a suppression of cancer cell aggregation, adhesion, and metastasis $[19,20]$. LCP acts as a ligand for GAL-3, which plays a critical role in the tumorigenesis and cancer progression [21-25]. Moreover, LCP also exhibits anti-metastatic effects on cancer cells in vivo and in vitro [26,27]. Clinical trials with LCP indicated an elevation in prostate specific antigen doubling time which is a symbol of progression slowing of prostate cancer [28], a significant improvement of patients life quality, and stabilization of disease progression in patients with advanced tumor [29]. Taken together, LCP has shown promise as an anti-cancer agent for cancer prevention and treatment. In this report, we have investigated the effect of LCP on cell proliferation, migration and death of gastrointestinal cancer cells using the AGS gastric cancer cell-line and the SW-480 colorectal cancer cell-line both in vitro and in vivo. The related mechanisms of action of LCP were studied with respect to cell cycle progression, cell viability, and apoptosis through caspase-dependent pathway, and inhibition of metastasis by reversion of epithelial-mesenchymal transition (EMT).

\section{Materials and methods}

\section{Chemical reagents}

PYKTIN $^{\circledR}$ LCP was from Centrax International, Inc. (139 Mitchell Ave., Suite 101, South San Francisco, CA94080, USA). Primary antibodies used in this study included those against Cyclin A, Cyclin B1, GAL-3, E-cadherin, Snail, Twist, Vimentin and Zeb1 were purchased from cell signaling; and those against Survivin, Bcl-xL, Caspase-3, and Caspase- 8 were from Sigma (St. Louis, MO). Alpha-tubulin antibody was from Santa Cruz Technologies. HRP-conjugated anti-rabbit or anti-mouse secondary antibodies were from GE Healthcare. 5-FU was purchased from APP Pharmaceuticals.

\section{Cell culture and treatments}

AGS gastric cancer cell-line and SW-480 colorectal cancer cell-line were grown in RPMI 1640 (Gibco BRL, Life Technologies, Inc., Rockville, MD, USA) with $2 \mathrm{~mol} / \mathrm{L}$ L-glutamine, $10 \%$ heat-inactivated fetal bovine serum (FBS, Gibco BRL, Life Technologies, Inc.) and 5\% mixture of $100 \mathrm{U} / \mathrm{mL}$ penicillin, $100 \mu \mathrm{g} / \mathrm{mL}$ streptomycin, $0.25 \mu \mathrm{g} / \mathrm{mL}$ amphotericin B (antibiotic-antimycotic, Gibco BRL, Life Technologies, Inc.), respectively. After sub-cultured for $24 \mathrm{hrs}$, exponentially growing cell suspensions were distributed into $25-\mathrm{cm}^{2}$ cell culture flasks at a density of $5 \times 10^{4}$ cells $/ \mathrm{mL}$ ( $5 \mathrm{~mL}$ medium). Cells were routinely examined for mycoplasma contamination, then maintained in a fully-humidified incubator in consisting of $50 \mathrm{~mL} / \mathrm{L} \mathrm{CO}_{2}$ in air at $37^{\circ} \mathrm{C}$. All experiments were performed with cells in the logarithmic phase of growth. For treatment, various doses of LCP (i.e., 0.625, 1.25, 2.5, 5.0, and 10.0 $\mathrm{mg} / \mathrm{ml}$ ), 5-FU (i.e., 25, 50, 100, 200, and $400 \mu \mathrm{M}$ ), or their combination $(5.0 \mathrm{mg} / \mathrm{ml} \mathrm{LCP}$ and $200 \mu \mathrm{M} 5$-FU) were added to the medium directly before detection.

\section{MTT assay}

Cells at a density of $5 \times 10^{3}$ cells/well were grown in flat-bottomed 96-well cell culture plates in appropriate medium supplemented with $2 \%$ heat-inactivated FBS. Then, the cells were treated with graded concentrations of LCP, 5-FU or their combination for $24 \mathrm{hrs}$. Twenty $\mu \mathrm{l}$ of MTT (3-(4,5Dimethylthiazol-2-yl)-2,5-diphenyltetrazolium bromide) reagent $(5.0 \mathrm{mg} / \mathrm{ml}$; Sigma, St Louis, MO, USA) were added to each well and then incubated at $37^{\circ} \mathrm{C}$ for $4 \mathrm{hrs}$. After removing the media, $200 \mu \mathrm{l}$ of dimethyl sulfoxide was added and placed at room temperature for $30 \mathrm{~min}$ to dissolve the formazan crystals. The absorbance was detected by a microplate 
reader (Bio-Rad, Hercules, CA, USA) at a wavelength of $60 \mathrm{~nm}$.

\section{Colony formation assay}

Cells were treated with different concentrations of LCP, 5-FU or their combination for $24 \mathrm{hrs}$ and colonies were allowed to establish themselves in drug-free culture medium for 10 days. Any colony that contained more than 50 cells was considered a viable clonogenic cell. Colonies were counted after staining with $0.1 \%$ trypan blue in $50 \%$ ethanol. The experiment was performed three times for each treatment.

\section{Flow cytometry}

For cell cycle analysis, both cell-lines were treated with LCP (5.0, and $10.0 \mathrm{mg} / \mathrm{ml}), 5-\mathrm{FU}$ (200, and $400 \mu \mathrm{M})$, or their combination $(5.0 \mathrm{mg} / \mathrm{ml} \mathrm{LCP}$ and $200 \mu \mathrm{M}$ 5-FU) for $24 \mathrm{hrs}$, and then fixed in chilled $80 \%$ ethanol. The fixed cells were incubated with a solution containing $100.0 \mu \mathrm{g} / \mathrm{mL}$ RNase in a $37^{\circ} \mathrm{C}$ water-bath for $45 \mathrm{~min}$. Then, $25 \mu \mathrm{L}$ of propidium iodide (final concentration of $50.0 \mu \mathrm{g} / \mathrm{ml}$ ) was added to cells and incubated in a $37^{\circ} \mathrm{C}$ water-bath for another 15 min.

\section{Western immunoblotting}

Protein concentrations were quantified using a Bio-Rad protein assay. Whole-cell proteins were separated on an 8\% SDS-polyacrylamide gel, transferred to a polyvinylidene difluoride (PVDF) membrane (Bio-Rad), and then probed with the indicated primary antibodies overnight at $4^{\circ} \mathrm{C}$. Washed blots were then incubated with horseradish peroxidase-conjugated anti-rabbit, anti-mouse, or anti-goat antibody (Santa Cruz Biotechnology, CA, USA) respectively for $1 \mathrm{hr}$ at room temperature. Blots were developed using the peroxidase reaction and visualized with enhanced chemiluminescence (ECL) detection system (Bio-Rad).

\section{Immunohistochemical staining}

The immunohistochemical analysis of proteins was performed according to a standard protocol. The immunohistochemical staining score (ISS) was determined by three independent pathologists based on combining the staining frequency and intensity as previously described [30-32].

\section{Human tumor xenografts in athymic nude mice}

Female nude mice, aged 5- to 6-weeks (Zhejiang Province Experimental Animal Center, China) were housed in a sterile environment with micro-isolator cages and allowed access to water and chow ad libitum. Approximately $1 \times 10^{6}$ cells were resuspended in $100 \mu \mathrm{l}$ of PBS (phosphate-buffered saline solution) and injected sub-cutaneously into the flanks of nude mice. Once the tumor was measurable, mice were treated daily with $5-\mathrm{FU}$ at $25 \mathrm{mg} / \mathrm{kg}$ by i.p. injection, or $1.0 \%, 2.5 \%$ and $5.0 \%(\mathrm{wt} / \mathrm{vol}) \mathrm{LCP}$ by oral gavage [27], or by their combination, respectively. LCP was dissolved in drinking water. 5-FU was supplied as a stock solution. Mice were treated for 7 days a week, and terminated after 21 days of treatment. Tumor growth was monitored by calipers, and tumor volumes were calculated according to the formula 0.5 $\times$ length $\times$ width $^{2}$. Mice were euthanized when tumors reached a size of approximately $1.0 \mathrm{~cm}^{3}$. Guidelines for the humane treatment of animals were followed as approved by the local Animal Care and Use Committee, Zhejiang Province Experimental Animal Center, China.

\section{TUNEL assay}

Apoptotic cell death in tumor xenograft tissue sections was determined by TUNEL (Terminal deoxynucleotidyl transferase-mediated dUTP nick end labeling) assay using the TdT-FragEL DNA Fragmentation Detection kit (EMD). Briefly, sections were digested with proteinase $\mathrm{K}$, and endogenous peroxidase activity was blocked with $3 \%$ hydrogen peroxide in $10 \mathrm{mM}$ Tris ( $\mathrm{pH}$ 8.0). The sections were then placed in equilibration buffer and incubated with the TdT enzyme in a humid chamber at $37^{\circ} \mathrm{C}$ for 1.5 hrs. The apoptotic nuclei were stained by 3,3'-diaminobenzidine and observed by light microscopy. We manually counted the number of positively stained nuclei and the percentage of positive cells, and the total number of cells was calculated for each image.

\section{Statistical analyses}

Results were presented relative to the untreated controls. Values represent the means \pm SD of a minimum of three replicate determinations. Data were analyzed by the Duncan test following the analysis of variance (ANOVA) procedure when multiple comparisons were made. Differences were considered significant when an alpha value was $P<$ 0.05 .

\section{Results}

\section{LCP inhibits both AGS gastric cancer and SW-480 colorectal cancer cell growth in vitro}

To test the effectiveness of LCP on the cell viability of gastrointestinal cancer, we used AGS gastric cancer cells and SW-480 colorectal cancer cells. These cells were treated individually with $\operatorname{LCP}(0.625$, $1.25,2.5,5.0$, and $10.0 \mathrm{mg} / \mathrm{ml}), 5$-FU $(25,50,100,200$, and $400 \mu \mathrm{M})$, or their combination $(5.0 \mathrm{mg} / \mathrm{ml} \mathrm{LCP}$ 
and $200 \mu \mathrm{M} 5$-FU) for $24 \mathrm{hrs}$. The effects of LCP and 5 -FU on cell viability was assessed by the MTT assay. We observed that the effect of LCP on both cell-lines was similar and was dose-dependent. Cell viabilities of AGS and SW-480 cells were decreased to $76 \%$ and $72 \%$ respectively when treated with LCP at a concentration of $5.0 \mathrm{mg} / \mathrm{ml}$ for $24 \mathrm{hrs}$. The percentage of inhibition on cell viability with different concentration of LCP treatment demonstrated a significant difference as compared with untreated cells in parallel, respectively (all $P<0.05$; Figure 1A). Results showed that both cell-lines were relatively more sensitive to 5-FU treatment compared to that treated by LCP. In SW-480 cells, there was $38 \%$ reduction in cell viability with 5 -FU at $25 \mu \mathrm{M}$ concentration. However, in AGS cells, 5-FU at $25 \mu \mathrm{M}$ reduced cell viability by approximately $45 \%$ as compared to control (Figure 1B). Overall, both agents elicited decreased cell viability in both SW-480 and AGS cells in a dose-dependent manner. Significant effects elicited by single LCP $(5.0 \mathrm{mg} / \mathrm{ml})$ or single 5 -FU $(200 \mu \mathrm{M})$ or their combination $(5.0 \mathrm{mg} / \mathrm{ml} \mathrm{LCP} \mathrm{+}$ $200 \mu \mathrm{M} 5$-FU) treatment on both AGS and SW-480 cells were observed as compared to the control group, respectively (all $P<0.05$ ). The inhibitory ability of both AGS and SW-480 cells by combined treatment (5.0 $\mathrm{mg} / \mathrm{ml} \mathrm{LCP}+200 \mu \mathrm{M} 5-\mathrm{FU})$ was higher than that seen by single 5-FU $(200 \mu \mathrm{M})$ treatment. However, there was no significant difference between them $(P>0.05)$. It is notable that the inhibitory ability of both AGS and SW -480 cells by combined treatment $(5.0 \mathrm{mg} / \mathrm{ml} \mathrm{LCP}$ $+200 \mu \mathrm{M} 5$-FU) or single 5-FU $(200 \mu \mathrm{M})$ treatment of both AGS and SW480 cells was significantly increased as compared that mediated by single LCP $(5.0 \mathrm{mg} / \mathrm{ml})$ treatment (all $P<0.05$; Figure $1 C$ ).
$1 \mathrm{~A}$
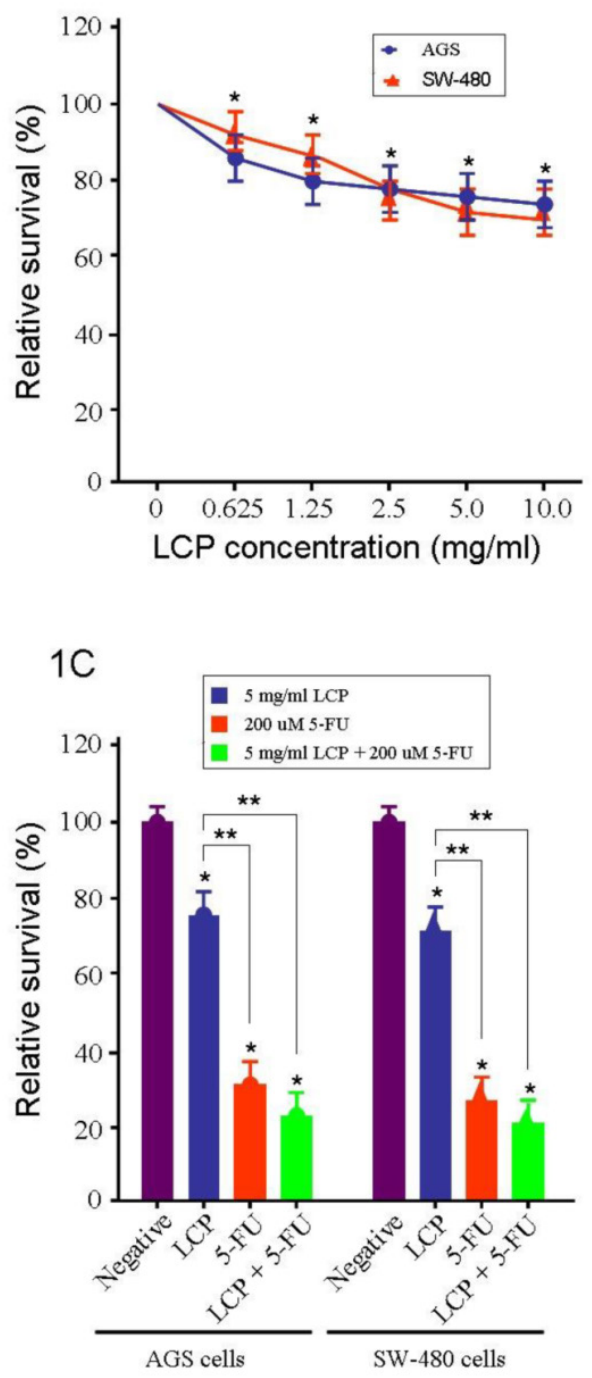

1B

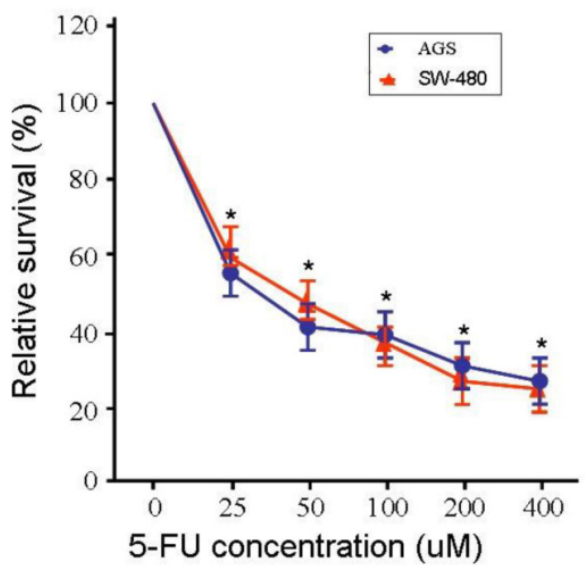

1D

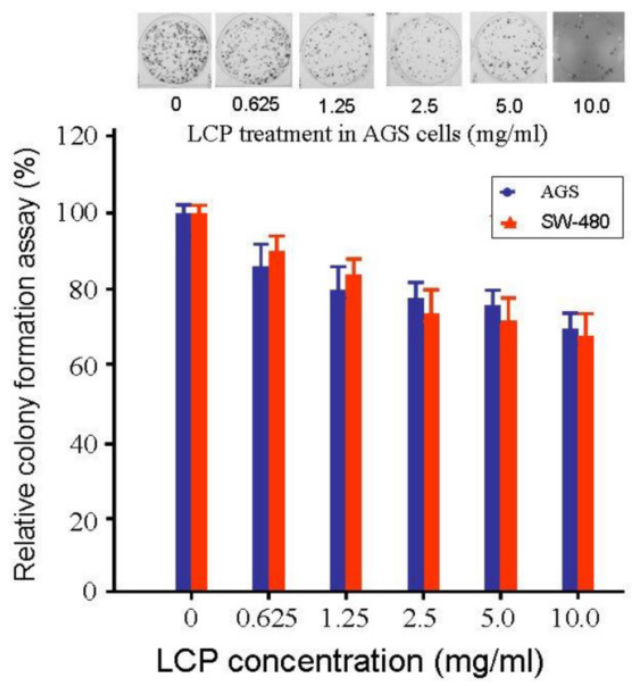

Figure 1. Cytotoxicity of LCP on both AGS gastric cancer and SW-480 colorectal cancer cell growth in vitro. IA, AGS and SW-480 cells were treated with different concentration of LCP for $24 \mathrm{hrs}$ and the cell viability was measured by MTT method. The percentage of inhibition on cell viability with LCP treatment demonstrated a concentration dependent manner and having significant difference as compared with parallel untreated cells, respectively $(*$ : $P<0.05)$. IB, AGS and SW-480 cells were treated with different concentration of 5-FU for $24 \mathrm{hrs}$ and the cell viability was measured by MTT method. The percentage of inhibition on cell viability with 5-FU treatment also demonstrated a concentration dependent manner and having significant difference as compared with parallel untreated cells, respectively (*: $P<0.05)$. Moreover, both cell-lines were relatively more sensitive to 5-FU treatment compared to that treated by LCP. IC, Compared with the control group (Negative), there were significant effects of single LCP $(5.0 \mathrm{mg} / \mathrm{ml})$ or single 5 -FU $(200$ $\mu \mathrm{M})$ or their combination $(5.0 \mathrm{mg} / \mathrm{ml} \mathrm{LCP} \mathrm{+}$ $200 \mu M$ 5-FU) treatment on both AGS and SW-480 cells, respectively $(* P<0.05)$. The inhibitory ability of both AGS and SW-480 cells by their combination $(5.0 \mathrm{mg} / \mathrm{ml} \mathrm{LCP} \mathrm{+}$ $200 \mu \mathrm{M} 5$-FU) was higher than that by single 5 -FU $(200 \mu \mathrm{M})$ treatment, but there was no significant difference between them $(P>0.05)$. The comparison of the percentage of inhibition on cell viability among $5.0 \mathrm{mg} / \mathrm{ml}$ LCP, $200 \mu \mathrm{M}$ 5-FU and their combination (5.0 $\mathrm{mg} / \mathrm{ml} \mathrm{LCP}+200 \mu \mathrm{M}$ 5-FU) treatment. The inhibitory ability of both AGS and SW-480 cells by their combination LCP $(5.0 \mathrm{mg} / \mathrm{ml})$ and 5-FU $(200 \mu \mathrm{M})$ or single 5 -FU $(200 \mu \mathrm{M})$ was significantly increased than that mediated by single LCP $(5 \mathrm{mg} / \mathrm{ml})$ (**: $P<0.05)$. ID, The effect of LCP on cell proliferation in AGS and SW-480 cells was tested by colony assay. 10 days after a different range of LCP treatment, each colony which contained more than 50 cells was considered to represent a viable clonogenic cell. The inhibitory ability of colony formation showed a concentration dependent manner. All assays represented the mean \pm SD of two independent experiments with triplicate dishes. 


\section{LCP suppresses cell proliferation and cell cycle in gastrointestinal cancer cells}

The effect of LCP on cell proliferation in AGS and SW-480 cells was tested by colony-forming assay (Figure 1D). Ten days after a different range of LCP treatments, each colony that contained more than 50 cells was considered to represent a viable clonogenic cell. Approximately $76 \%$ of AGS cells and $72 \%$ of SW-480 cells, survived at a concentration of 5.0 $\mathrm{mg} / \mathrm{ml}$, while in AGS and SW480 cells, cell proliferation was dampened by approximately $62 \%$ and $55 \%$ respectively at $25 \mu \mathrm{M} 5$-FU (Figure $1 \mathrm{~A}$ and B).

The effect of LCP $(5.0$, and $10.0 \mathrm{mg} / \mathrm{ml})$ on AGS and SW-480 cells showed cell cycle specificity, and there was no difference seen between AGS and SW-480 cells (see Figure 2A1-3 and 2B1-2). There was no significant change in cell cycle after $0.624-2.5$ $\mathrm{mg} / \mathrm{ml}$ treatment for $24 \mathrm{hrs}$, which was similar to the control group. The fraction of G0/G1 in AGS cells decreased from $89.1 \%$ to $52.9 \%$, and $48.2 \%$ respectively after 5.0 , and $10.0 \mathrm{mg} / \mathrm{ml} \mathrm{LCP}$ treatment for $24 \mathrm{hrs}$. By contrast, the fraction of cells in the $\mathrm{G} 2 / \mathrm{M}$ phase of the cell cycle increased from $6.7 \%$ to $32.2 \%$, and $41.7 \%$, respectively (Figure 2A1-3, 2B-1). However, the effects of 5-FU (200, and $400 \mu \mathrm{M})$ on AGS and SW-480 cells showed remarkable cell cycle specificity, even at a treatment dose of $25 \mu \mathrm{M}$ 5-FU. The fraction of AGS cells in the G0/G1 phase of the

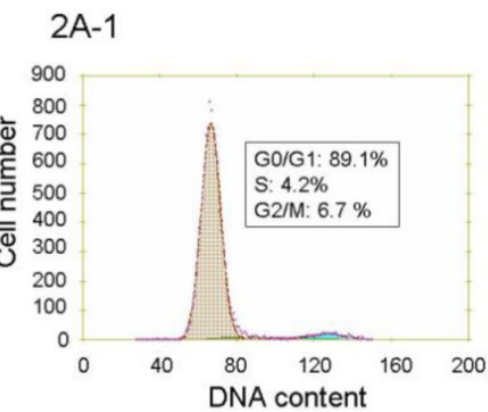

$$
2 \mathrm{~A}-2
$$

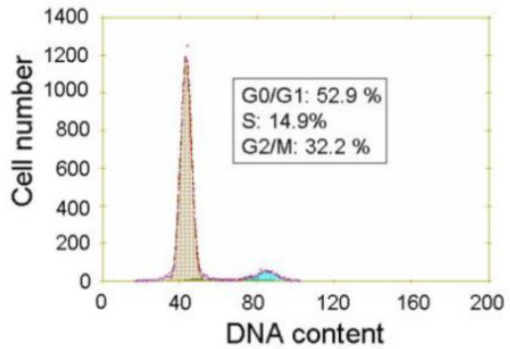

cell cycle decreased from $89.1 \%$ to $31.2 \%$, and $28.9 \%$ after 200, and $400 \mu \mathrm{M} 5$-FU treatment respectively for $24 \mathrm{hrs}$. By contrast, the fraction of cells in the G2/M phase of the cell cycle increased from $6.7 \%$ to $38.9 \%$, and $48.5 \%$, respectively. The effect of combined treatment with $5 \mathrm{mg} / \mathrm{ml} \mathrm{LCP}$ and $200 \mu \mathrm{M} 5$-FU on AGS cell cycle showed a greater change than that seen following treatment with LCP or 5-FU alone; however, there was no significant difference when comparing combined or single treatments $(P>0.05$; Figure 2B-3).

In addition, to better understand the effects of LCP on cell cycle of both cell-lines, we evaluated the expression of two cell cycle-related enzymes (i.e., Cyclin A and Cyclin B1) in both cell-lines according to different treatment concentrations of LCP. In these experiments, 5-FU treatment was used as a comparison. There was no significant change in Cyclin A levels in both cell-lines under LCP treatment, although a notable reduction was seen at various concentrations of 5-FU treatment. However, LCP and 5-FU down-regulated the expression of Cyclin B1 in both cell-lines. Both LCP and 5-FU inhibited expression of Cyclin B1 in both cell-lines at low concentrations (i.e., $0.625 \mathrm{mg} / \mathrm{ml}$ and $25 \mu \mathrm{M}$ respectively). Both LCP and 5-FU or their combination decreased Cyclin B1 levels in AGS and SW-480 cells in a dose-dependent manner (Figure 3A and 3B).
2B-2

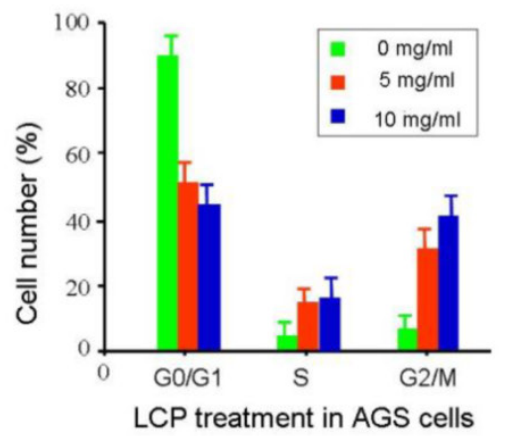

\section{B-1}

Figure 2. Flow cytometry analysis of cell cycle in AGS and SW-480 cells after LCP treatment. The percentage of phase population of cell cycle in AGS cells with different concentration of LCP treatment for $24 \mathrm{hrs}(\mathbf{2 A - 1}, 0 \mathrm{mg} / \mathrm{ml} ; \mathbf{2 A - 2}, 5.0 \mathrm{mg} / \mathrm{ml} ; \mathbf{2 A - 3}, 10.0 \mathrm{mg} / \mathrm{ml} \mathrm{LCP})$. Flow cytometry analysis of the phase population of AGS cells $(\mathbf{2 B}-1)$ and SW-480 cells (2B-2) after LCP treatment for 24 hrs, showing the effect of different concentrations of LCP on the cell cycle. 2B-3, Effect of different concentration of 5-FU or the combination of 5-FU and LCP on the cell cycle in AGS cells. All assays represented the mean \pm SD of triplicate independent experiments. 

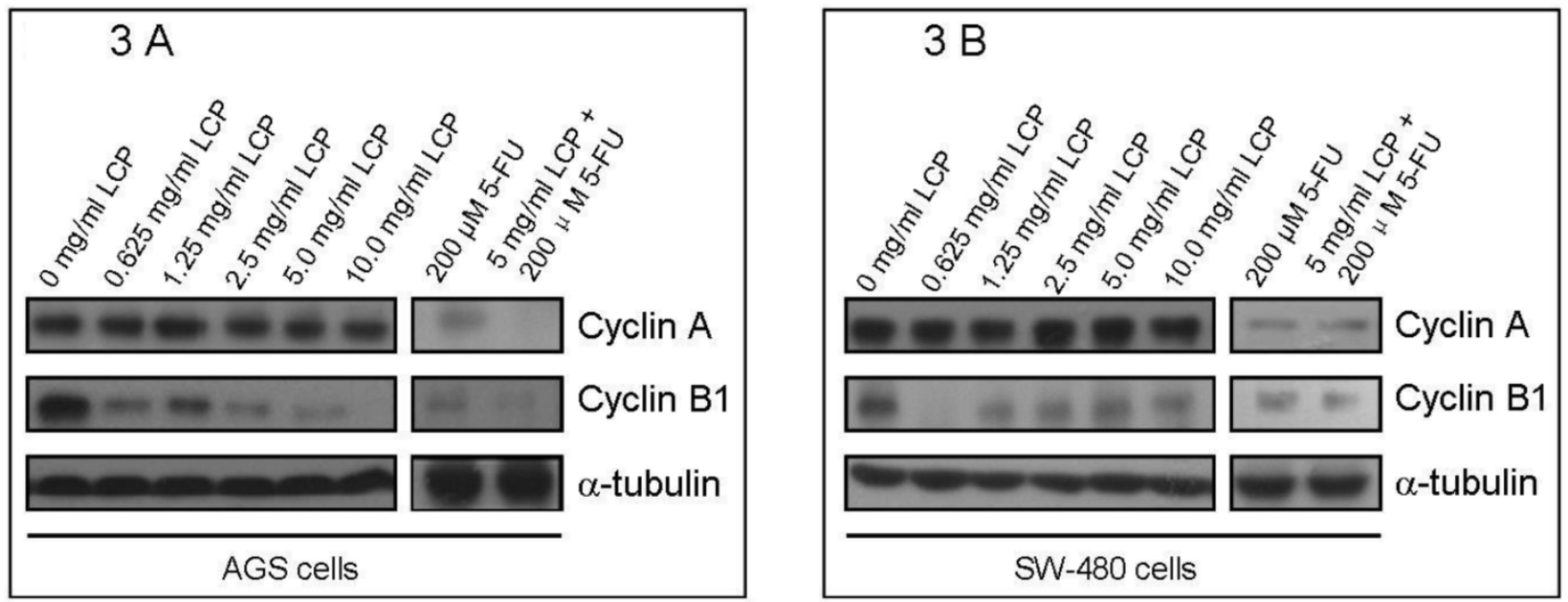

Figure 3. Western blot analysis of the expression of cell cycle-related enzymes (Cyclin A and Cyclin BI) in AGS cells (3A) and SW-480 cells (3B) according to different concentration of LCP treatment. 5-FU treatment was used as a comparison. The amount of protein was normalized by comparing the intensity of the $\alpha$-tubulin band.

\section{Effect of LCP on tumor xenograft growth}

After establishing the efficacy of LCP on gastrointestinal cancer cells in vitro, we further designed in vivo experiments to test the efficacy of LCP against AGS and SW-480 xenograft models in nude mice. The treatments were initiated 10 days after AGS and SW-480 cells were transplanted into nude mice. The average tumor weight of the LCP treated group was significantly smaller (AGS tumor: $0.38 \mathrm{~g}$, and SW-480 tumor: $0.41 \mathrm{~g}$ ) than that of the untreated control group (AGS tumor: $0.85 \mathrm{~g}$, and SW-480 tumor: $0.87 \mathrm{~g})$, which was similar to the 5 -FU $(25 \mathrm{mg} / \mathrm{kg})$ treated group $(0.24 \mathrm{~g}$; all $P<0.05)$. We found a dose-dependent relationship between the tumor inhibition effect and the concentration of LCP treatment. We also tested the effect of $5.0 \%(\mathrm{wt} / \mathrm{vol})$ LCP and $25 \mathrm{mg} / \mathrm{kg} 5$-FU combination on AGS ( $0.19 \mathrm{~g})$ or SW-480 $(0.20 \mathrm{~g})$ tumor xenografts as a comparison. Results showed that their combined treatment was more effective at inhibiting in vivo tumor growth than that shown by single LCP or 5-FU treatment (Figure 4A). Moreover, we found that there was no significant difference between AGS and SW-480 cells receiving the same dose of LCP or 5-FU or following their combined treatment. During this period, each mouse was manually examined for body weight every week and there were no significant difference between the untreated group of mice and their treated counterparts (Figure 4B).

\section{LCP inhibits GAL-3 levels, increases reversion of epithelial-mesenchymal transition (EMT) and suppresses tumor metastasis in vitro and in vivo}

To evaluate the effect of LCP treatment on GAL-3 level, we treated AGS and SW-480 cells with LCP $(5.0$ and $10.0 \mathrm{mg} / \mathrm{ml})$ for $24 \mathrm{hrs}$ and detected
Galectin-3 level by Western blot. We observed that LCP treatment decresed GAL-3 level compared with untreated control, but not in a dose dependent (Figure 5A, B). To elucidate the effect of LCP on the expression of EMT markers, we treated both cell-lines with two different doses $(5.0$ and $10.0 \mathrm{mg} / \mathrm{ml})$ and tested by Western blot. LCP treatment markedly enhanced the expression of the epithelial marker E-cadherin, and markedly decreased the expression of the mesenchymal markers Snail, Twist, Vimentin and Zeb1, which indicated the suppression of EMT in both cell-lines (Figure 5A, B). There were no significant differences in expression of EMT makers in both cell-lines when treated with higher dose $(10.0 \mathrm{mg} / \mathrm{ml})$ of LCP as compared to the relatively lower dose of 5.0 $\mathrm{mg} / \mathrm{ml} \mathrm{LCP}$.

In AGS and SW-480 xenograft nude mice experiment, once the tumor was measurable, mice were treated daily with 5 -FU at $25 \mathrm{mg} / \mathrm{kg}$ by i.p. injection, or $1.0 \%, 2.5 \%$ and $5.0 \%$ (wt/vol) LCP by oral gavage, or by their combination, respectively. Results showed that LCP treatment significantly altered the expression of galcetin-3 and EMT markers such as E-cadherin and Twist in a dose- dependent manner as compared with controls (all $P<0.05$; Figure 5C) These results are consistent with our in vitro observations that showed a critical role of LCP treatment in the growth and metastasis of gastrointestinal cancer.

\section{Effect of LCP on apoptosis in gastrointestinal cancer cells}

To analyze the effect of LCP treatment on induction of apoptosis in AGS cells and SW-480 cells, apoptosis-related proteins were determined by Western blot in both cell-lines. We measured the expression of apoptotic-related protein levels, which included two anti-apoptotic proteins (i.e., Bcl-xL and 
Survivin) and two pro-apoptotic proteins (i.e., Caspase-3 and Caspase-8). There was no significant difference in the expression of Caspase-3 and Caspase- 8 in both cell-lines according to treatment with $10.0 \mathrm{mg} / \mathrm{ml} \mathrm{LCP}$; however, treatment with 200 $\mu \mathrm{M}$ 5-FU enhanced the expression of Caspase-3 and Caspase- 8 in both cell-lines (Figure 6A, B). In addition, $200 \mu \mathrm{M}$ 5-FU was more effective at decreasing Survivin expression in SW-480 cells than

$4 \mathrm{~A}$
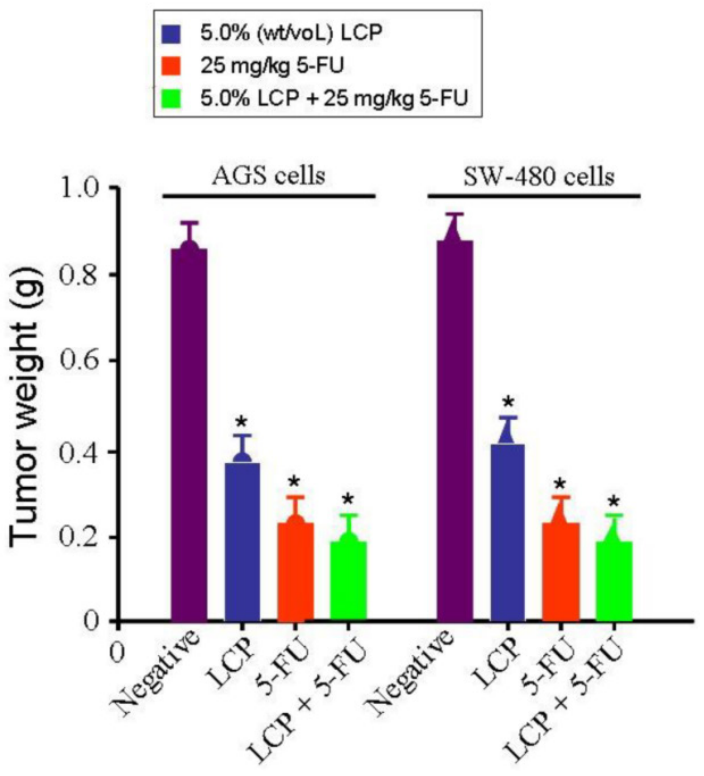

Figure 4. Effect of LCP on tumor xenografts growth. 4A, shows the tumor mass ( $\mathrm{g}$ ) that was measured on the final experiment day immediately after the tumor tissue was removed from the mouse by surgical excision. The average tumor mass is indicated as a bold bar in each group. $P$ value was compared with untreated group (Negative). The average tumor weight of LCP treated group was significantly smaller than that of untreated control group, being similar to 5-FU treated group. 4B, during this period, each mouse was manually examined for body weight every week and there were not significant differences between untreated group mice and treated group mice. All experiments represented the mean \pm SD of triplicate independent experiments.
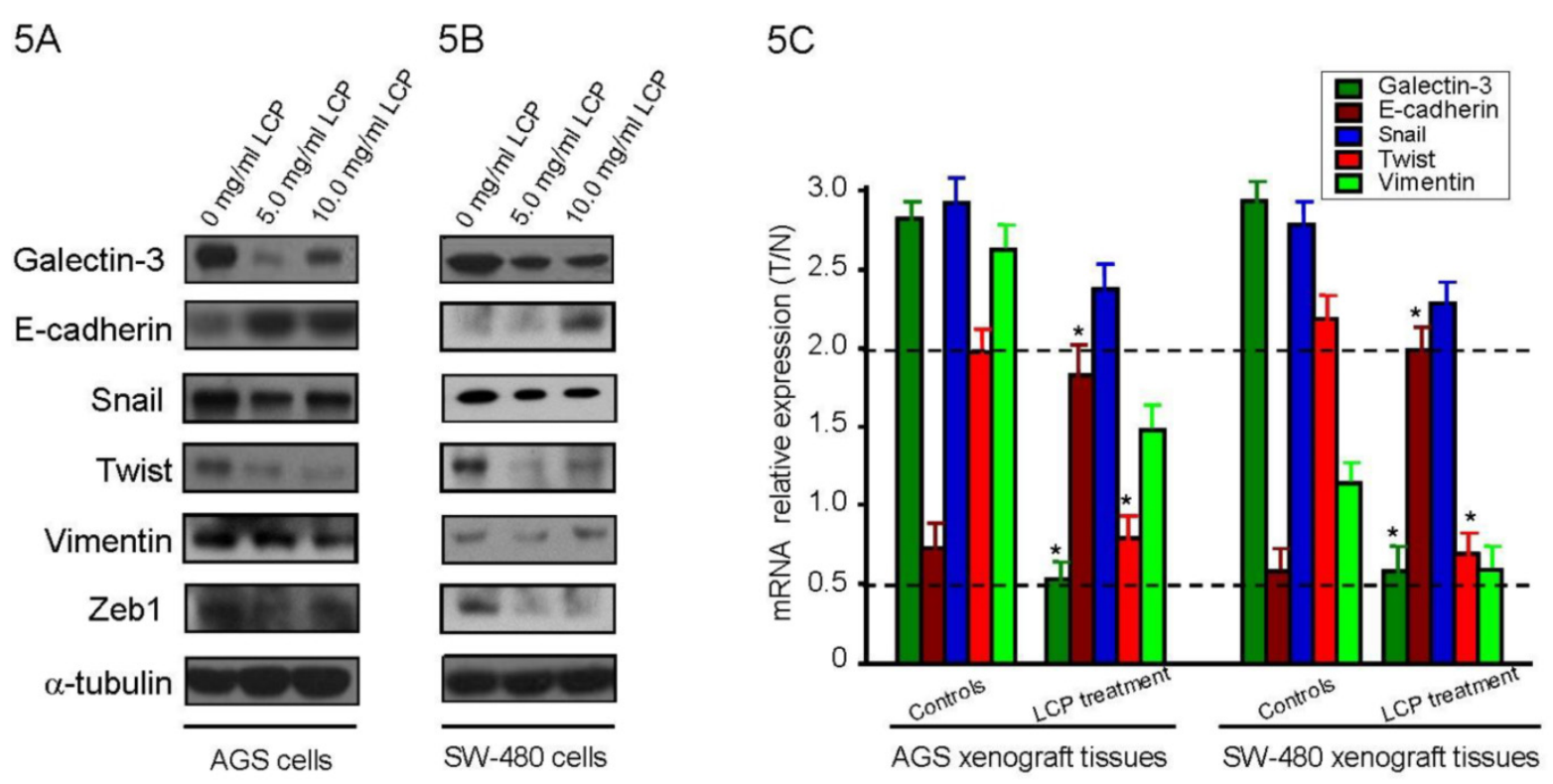

Figure 5. Effect of LCP treatment on Galcetin-3 and EMT-related gene expression. Alteration of Galcetin-3 and EMT markers expression after different concentration of LCP treatment for 24 hrs in AGS cells $\mathbf{( 5 A )}$ and SW-480 cells $(\mathbf{5 B})$. The amount of protein was normalized by comparing the intensity of the $\alpha$-tubulin band. $\mathbf{5 C}$, In AGS and SW-480 xenograft nude mice experiment, when the tumor was measurable, mice were treated daily with 5 -FU at $25 \mathrm{mg} / \mathrm{kg}$ by i.p. injection, or different dose of LCP by oral gavage, or by their combination, respectively. Results showed that $5.0 \%$ (wt/vol) LCP treatment significantly alters the expression of Galcetin-3, E-cadherin and Twist at mRNA level as compared with controls (all $P<0.05$ ). GAPDH was used as reference. All experiments represented the mean \pm SD of triplicate independent experiments. 
$6 \mathrm{~A}$

$6 \mathrm{~B}$

$6 \mathrm{C}$
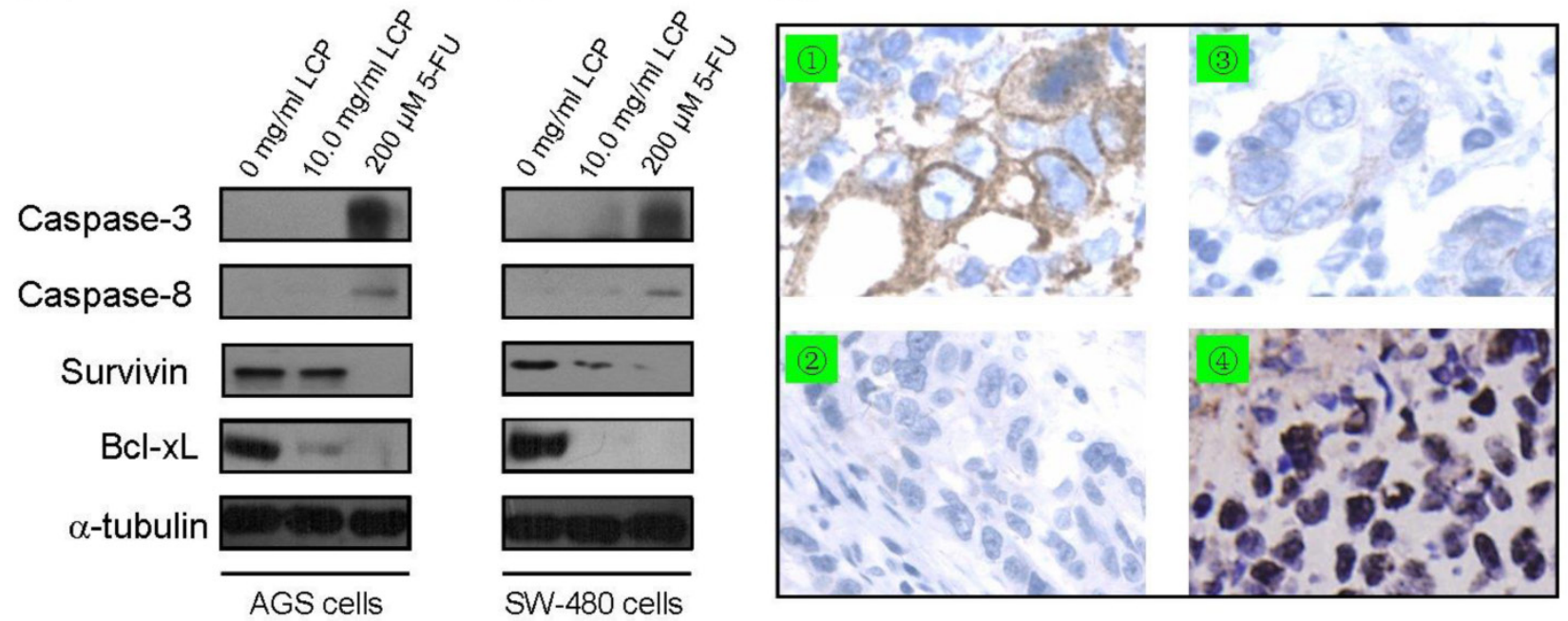

Figure 6. Effect of LCP on apoptosis in gastrointestinal cancer cells. The expression of apoptotic-related protein levels which including two anti-apoptotic proteins (Bcl-xL and Survivin) and two pro-apoptotic proteins (Caspase-3 and Caspase-8) were determined by Western blot in AGS cells (6A) and SW-480 cells (6B) according to LCP $(10.0 \mathrm{mg} / \mathrm{ml})$ or $5-\mathrm{FU}(200 \mu \mathrm{M})$ treatment. $6 \mathrm{C}$, Immunohistochemical staining of Bcl-xL and TUNEL analysis of apoptosis in AGS xenograft tissues. Control group (without LCP treatment): (1) Bcl-xL protein by IHC; (2) Apoptosis by TUNEL. LCP treated group (10.0 mg/ml LCP): (3) Bcl-xL protein by IHC; (4) apoptosis by TUNEL.

\section{Discussion}

Recently there has been increasing interest in the potential role of low-molecular-weight citrus pectin (LCP) in the prevention and reduction of malignant transformation and carcinogenesis. Accumulating evidence suggests that small molecular weight pectin fragments, which are rich in galactans, can bind to the carbohydrate recognition domain (CRD) on the pro-metastatic protein GAL-3 [21-25]. This binding may inhibit a tumor by blocking the interaction of GAL-3 with other proteins and peptides; however, its exact mechanisms remain unclear. Our results indicated that the anti-tumor activity of LCP alone decreased the level of GAL-3, which is an important gene in tumor metastasis, and which results in reversion of epithelial-mesenchymal transition (EMT), reduced cell proliferation, increased suppression of anti-apoptotic proteins (e.g., Bcl-xL and Survivin) with the collective action of promoting caspases-mediated apoptosis and inhibition of tumor cell growth.

Although it was previously reported that LCP can effectively inhibit the growth of various tumors and suppresses tumor cell metastasis by intercepting the adhesion and aggregation of cancer cells [19-29], our findings demonstrated synergy, in that we have demonstrated a process of chemoprevention of LCP in gastrointestinal cancer cells both in vitro and in vivo. In this study, we used the MTT assay to demonstrate that both of LCP and 5-FU elicited decreased cellular viability of both AGS and SW-480 cells in vitro following treatment with LCP concentration of $(0.625$ $-10.0) \mathrm{mg} / \mathrm{ml}$ and $5-\mathrm{FU}$ concentrations of $25-400 \mu \mathrm{M}$ respectively in a dose-dependent manner (Figure 1A, B). We observed that the effect of LCP on both cell-lines was similar, and both cell-lines were relatively more sensitive to 5-FU treatment as compared to that treated by LCP (Figure 1A, B). Of course, the advantage of LCP was also obvious, in that it displayed few side effects. However, the anti-tumor activity of 5-FU was found to vary with the type of cancer cell. In SW-480 cells, there was a $38 \%$ reduction in cell viability with $5-\mathrm{FU}$ at a concentration of $25 \mu \mathrm{M}$. However, in AGS cells, we found that 5-FU, at a concentration of $25 \mu \mathrm{M}$, reduced cell viability by approximately $45 \%$ as compared to the control. Compared with the control group (Negative), there was significant effects of single treatment by LCP (5.0 $\mathrm{mg} / \mathrm{ml}$ ) on both AGS and SW-480 cells, an observation which was similar to that seen following single treatment by 5 -FU $(200 \mu \mathrm{M})$ or when used in combination (i.e., $5.0 \mathrm{mg} / \mathrm{ml} \mathrm{LCP}+200 \mu \mathrm{M} 5-\mathrm{FU}$ ), respectively (all $P<0.05$ ). The inhibitory ability of a combination approach $(5.0 \mathrm{mg} / \mathrm{ml} \mathrm{LCP}$ and $200 \mu \mathrm{M}$ 5 -FU) or single use of 5-FU against both AGS and SW480 cells, was significantly increased as compared to that mediated by single treatment with LCP alone (all $P<0.05$; Figure 1C). However, there was a significant difference seen between the combination treatments (i.e., $5.0 \mathrm{mg} / \mathrm{ml} \mathrm{LCP}$ and $200 \mu \mathrm{M} 5-\mathrm{FU}$ ) and single 5-FU treatment $(P>0.05)$. However, even under these conditions, LCP could be used in combination with other therapies. Our data demonstrated that LCP had certain anti-tumor activities and was synergistic with 5 FU. More importantly, high dose LCP did not display any side-effect on body weight. Cell viability assays were shown dose-dependent reduction 
following LCP treatment (i.e., $0.625-10.0 \mathrm{mg} / \mathrm{ml}$ ) against cancer cells. Therefore, we evaluated LCP anti-tumor efficacy by a dose-dependent approach that ranged from 0.625 to $10.0 \mathrm{mg} / \mathrm{ml}$ against AGS and SW-480 cells by colony-forming assays. Cell proliferation was obviously inhibited by LCP at a dose of $10.0 \mathrm{mg} / \mathrm{ml}$, which reflected the formation of cell colonies (Figure 1D). This result was consistent with the cell viability assay and all results above collectively supported the hypothesis that LCP could inhibit gastrointestinal cancer cell growth in vitro.

Until now, the inhibition of LCP on cell cycle in cancer cells has not been reported. In this study, we tested the effect of LCP on cell cycle in gastrointestinal cancer cells. We found that there was no difference between AGS and SW480 cells (Figure 2A1-3 and 2B1-2), and there was no significant change in cell cycle dynamics after treatment with $0.625-2.5 \mathrm{mg} / \mathrm{ml}$ LCP for $24 \mathrm{hrs}$, which was similar to the control group. LCP treatment resulted in increased cell populations in the G2/M phase of the cell cycle and decreased populations in the $S$ phase of the cell cycle in a dose-dependent manner in both AGS and SW-480 cells (Figure 2B1-2). The remarkable cell cycle specificity was found in both AGS and SW-480 cells after 5-FU (i.e., at doses of 200, and $400 \mu \mathrm{M}$ ) treatment, and even following treatment by $25 \mu \mathrm{M}$ of $5-\mathrm{FU}$. The effect of the combination of $5.0 \mathrm{mg} / \mathrm{ml} \mathrm{LCP}$ and 200 $\mu \mathrm{M} 5$-FU on the cell cycle in AGS cells showed greater changes than those found by LCP or 5-FU treatment alone; however, there was no significant difference between their combination as compared the single treatment group $(P>0.05 ;$ Figure 2B-3). We also observed that the combination of $5.0 \mathrm{mg} / \mathrm{ml} \mathrm{LCP}$ and $200 \mu \mathrm{M} 5$-FU or $200 \mu \mathrm{M} 5$-FU alone was more effective at down-regulating Cyclin A and Cyclin B1 expression in both cell-lines cells than that mediated by treatment with LCP alone at $0.625-10.0 \mathrm{mg} / \mathrm{ml}$ (Figure 3A, B). However, there was no significant evidence of any effects of LCP on Cyclin A in both cell-lines when compared with controls. LCP treatment at $0.625-10.0 \mathrm{mg} / \mathrm{ml}$ markedly decreased the expression of Cyclin B1 in both cell-lines, but did so in an independent manner. Additionally, in vivo AGS and SW-480 tumor xenografted mice resulted in consistent observations to the in vitro results. We observed that both AGS and SW-480 cell-lines xenografted mice were more sensitive to the combination of $5.0 \%$ (wt/vol) LCP and $25 \mathrm{mg} / \mathrm{kg}$ 5-FU than was observed following single treatment with LCP or 5 -FU. A $25 \mathrm{mg} / \mathrm{kg}$ dose of 5 -FU that was used in this study was given to nude mice every day, which was more effective than low dose 5-FU at suppressing AGS or SW-480 tumor growth (Figure $3 \mathrm{~A}, \mathrm{~B})$. The effect of LCP on tumor suppression in xenografted mice was dose-dependent, which was similar to that shown for 5-FU. There was no significant difference in measuring tumor weight $(\mathrm{g})$ among any of the three groups including single LCP treatment or single 5-FU treatment or when these agents were used in combination (Figure 4A). There was also no significant difference in measuring mouse body weigh among all three groups, which suggested that high dose LCP did not display any marked side-effect on body weight (Figure 4B). Our work provided evidence again for the efficacy of LCP in reducing primary tumor burden in the gastrointestinal cancer xenograft model. These encouraging effects of LCP were supported by previously reported animal studies, which significantly decreased experimental metastasis and showed an impressive ability to form tumour colonies [19-29].

Although there was evidence from numerous studies suggesting that LCP could inhibit various steps in the process of tumor metastasis by interacting with GAL3, the details of the underlying mechanisms are still largely unknown. Our results have demonstrated the anti-tumor effect of LCP in gastrointestinal cancer cells, along with the potential mechanisms of how it may exert its anti-metastatic effects, particularly in relation to GAL3. This raises the possibility that LCP may be utilized in a potentially safe, non-toxic approach for preventing or reducing carcinogenesis and metastasis [33,34]. One of the important findings in our study was that LCP treatment could inhibit tumor metastasis in AGS and SW-480 cells through reversion of the EMT. EMT features were well correlated with the level of GAL3 expression, suggesting that the metastatic potential was positively regulated by GAL3, and that EMT features were inhibited by LCP treatment in gastrointestinal cancer cells. Consistent with such observations in an in vitro cell model, this hypothesis was further supported by our in vivo findings that LCP could inhibit the levels of GAL3, increase reversion of EMT and suppress tumor metastasis in tumor xenografted nude mice. However, the mechanism of reversion of EMT that was mediated by LCP treatment remains to be further studied.

Studies have shown that plant-derived chemopreventive agents induce multiple proapoptotic responses that induce apoptosis against a variety of caspase-family members, which is one of the critical protease mediators of apoptosis that are triggered by different stimuli $[35,36]$. However, in the present study, we found that LCP treatment did not noticeably activate initiator caspases, such as Caspase-8, followed by activation of effector Caspase-3 in AGS and SW-480 cells in vitro while 5-FU 
did (Figure 6A, B). It has been previously found that ceramide accumulation would induce cellular apoptosis by inhibiting the expression of Bcl-2 family proteins [37]. Our in vitro and in vivo studies demonstrating that LCP treatment inhibited the anti-apoptotic protein $\mathrm{Bcl}-\mathrm{xL}$ similar to that found for $5-\mathrm{FU}$, suggest involvement of the mitochondrial pathway (Figure 6) [38]. Survivin was strongly up-regulated in angiogenically stimulated endothelium in vitro and in vivo, which protects endothelial cells from apoptosis [39]. The down-regulation of Survivin was correlated with down-regulation of Bcl-xL by 5-FU treatment in SW-480 cells (Figure 6B), while the level of Survivin expression was not consistent with the level of Bcl-xL expression (Figure 6A). Therefore, some mechanism and the relationship between Survivin and Bcl-xL in inducing apoptosis in gastrointestinal cancer cells should be further researched. The expression of anti-apoptotic-related protein Bcl-xL and TUNEL assay results confirmed that apoptosis is an important pathway that was associated with the anti-tumor activity of LCP. Our in vivo results showed increased apoptotic activity that was correlated very well with our in vitro results. Taken together, these results suggested that LCP could be a promising chemopreventive agent that displayed anti-tumor properties in the gastrointestinal cancer in vitro and in vivo, showing in a dose-dependent manner. The concentration of $10.0 \mathrm{mg} / \mathrm{ml}$ in vitro and $5.0 \%$ (wt/vol) in vivo we have chosen is the highest concentration of LCP that could be dissolved at room temperature. To gain additional insights on the anti-tumor mechanisms of combination therapy, other non-apoptotic signaling pathways should be investigated.

\section{Acknowledgments}

This work was supported by the Scientific Research Grants in Traditional Chinese Medicine, Zhejiang Province of China (No. 2012ZB018), the research grants from National Natural Science Foundation of China (81372332, 81572822), Key Projects from Zhejiang Provincial Natural Science Foundation of China (LZ13H160002), partly sponsored by Zhejiang Provincial Program for the Cultivation of High-level Innovative Health talents (Ling ZQ), and the Major Training Personnel from Zhejiang Provincial Program for the Training and Development Project for 151 talents (Ling ZQ).

\section{Conflicts of interest}

This study is not related to any potentially competing financial or other interests.

\section{References}

1. Prasad S, Tyagi AK. Ginger and its constituents: role in prevention and treatment of gastrointestinal cancer. Gastroenterol Res Pract. 2015; 2015:142979.

2. Gajowik A, Dobrzyńska MM. Lycopene - antioxidant with radioprotective and anticancer properties. A review. Rocz Panstw Zakl Hig. 2014; 65:263-271.

3. Falasca M, Casari I, Maffucci T. Cancer chemoprevention with nuts. J Natl Cancer Inst. 2014; 106: 1-10.

4. Alfonso L, Ai G, Spitale RC. et al. Molecular targets of aspirin and cancer prevention. Br J Cancer. 2014; 111:61-67.

5. Ting H, Deep G, Agarwal C. et al. The strategies to control prostate cancer by chemoprevention approaches. Mutat Res. 2014; 760:1-15.

6. Baumeister P, Reiter M, Harréus U. Curcumin and other polyphenolic compounds in head and neck cancer chemoprevention. Oxid Med Cell Longev. 2012; 2012:902716.

7. Liang H, Yuan Q. Natural sulforaphane as a functional chemopreventive agent: including a review of isolation, purification and analysis methods. Crit Rev Biotechnol. 2012; 32:218-234.

8. Fresco P, Borges F, Marques MP. et al. The anticancer properties of dietary polyphenols and its relation with apoptosis. Curr Pharm Des. 2010; 16:114-134.

9. Antosiewicz J, Ziolkowski W, Kar S. et al. Role of reactive oxygen intermediates in cellular responses to dietary cancer chemopreventive agents. Planta Med. 2008; 74:1570-1579.

10. Stan SD, Kar S, Stoner GD. et al. Bioactive food components and cancer risk reduction. J Cell Biochem. 2008; 104:339-356.

11. Zubair H, Khan HY, Sohail A. et al. Redox cycling of endogenous copper by thymoquinone leads to ROS-mediated DNA breakage and consequent cell death: putative anticancer mechanism of antioxidants. Cell Death Dis. 2013; 4:e660.

12. Cerella C, Radogna F, Dicato M. et al. Natural compounds as regulators of the cancer cell metabolism. Int J Cell Biol. 2013; 2013:639401.

13. Thakur VS, Deb G, Babcook MA. et al. Plant phytochemicals as epigenetic modulators: role in cancer chemoprevention. AAPS J. 2014; 16:151-163.

14. Kassim OO, Copeland RL, Kenguele HM. et al. Antiproliferative activities of Fagara xanthoxyloides and Pseudocedrela kotschyi against prostate cancer cell lines. Anticancer Res. 2015; 35:1453- 1458.

15. Hong SW, Jung KH, Lee HS. et al. SB365, Pulsatilla saponin D, targets c-Met and exerts antiangiogenic and antitumor activities. Carcinogenesis. 2013; 34:2156-2169.

16. Li H, Huang J, Yang B. et al. Mangiferin exerts antitumor activity in breast cancer cells by regulating matrix metalloproteinases, epithelial to mesenchymal transition, and $\beta$-catenin signaling pathway. Toxicol Appl Pharmacol. 2013; 272:180-190.

17. Kaya M, Sousa AG, Crépeau MJ. et al. Characterization of citrus pectin samples extracted under different conditions: influence of acid type and $\mathrm{pH}$ of extraction. Ann Bot. 2014; 114:1319-1326.

18. Maxwell EG, Belshaw NJ, Waldron KW. et al. Pectin- an emerging new bioactive food polysaccharide. Trends in Food Science \& Technology. 2012; 24:64-73.

19. Nangia-Makker P, Conklin J, Hogan V. et al. Carbohydrate-binding proteins in cancer, and their ligands as therapeutic agents. Trends Mol Med. 2002; 8:187-192.

20. Kidd P. A new approach to metastasis cancer prevention: modified citrus pectin (MCP), a unique pectin that blocks cell surface lectins. Altern Med Rev. 1996; 1:4-10.

21. Glinsky VV, Raz A. Modified citrus pectin anti-metastatic properties: one bullet multiple targets. Carbohydr Res. 2009; 14:1788-1791.

22. Zou J, Glinsky VV, Landon LA. et al. Peptides specific to the galectin-3 carbohydrate recognition domain inhibit metastasis associated cancer cell adhesion. Carcinogenesis. 2005; 26:309-318.

23. Johnson KD, Glinskii OV, Mossine VV. et al. Galectin-3 as a potential therapeutic target in tumors arising from malignant endothelia. Neoplasia. 2007; 9:662-670.

24. Nangia-Makker P, Honjo Y, Sarvis R. et al. Galectin-3 induces endothelial cell morphogenesis and angiogensis. Am J Pathol. 2000; 156:899-909.

25. Inohara H, Raz A. Effects of natural complex carbohydrate (citrus pectin) on murine melanoma cell properties related to galectin-3 functions. Glycoconj J. $1994 ; 11: 527-532$

26. Jayaram S, Kapoor S, Dharmesh SM. Pectic polysaccharide from corn (Zea mays L.) effectively inhibited multi-step mediated cancer cell growth and metastasis. Chem Biol Interact. 2015; 235:63- 75.

27. Liu HY, Huang ZL, Yang GH. et al. Inhibitory effect of modified citrus pectin on liver metastases in a mouse colon cancer model. World J Gastroenterol. 2008; 14:7386-7391.

28. Guess BW, Scholz MC, Strum SB. et al. Modified citrus pectin (MCP) increases the prostate-specific antigen doubling time in men with prostate cancer: a phase II pilot study. Prostate Cancer Prostatic Dis. 2003; 6:301-304.

29. Azemar M, Hildenbrand B, Haering B. et al. Clinical benefit in patients with advanced solid tumors treated with modified citrus pectin: a prospective pilot study. Clin Med Oncol. 2007; 1:73-80

30. Ling ZQ, Ge MH, Lu XX. et al. Ndrg2 promoter hypermethylation triggered by helicobacter pylori infection correlates with poor patients survival in human gastric carcinoma. Oncotarget. 2015; 6: 8210-8225. 
31. Ling ZQ, Guo W, Lu XX. et al. A Golgi-specific protein PAQR3 is closely associated with the progression, metastasis and prognosis of human gastric cancers. Ann Oncol. 2014; 25:1363-1372.

32. Ling ZQ, Lv P, Lu XX. et al. Circulating methylated XAF1 DNA indicates poor prognosis for gastric cancer. PLoS One. 2013; 8:e67195.

33. Xu Y, Gu X, Gong M. et al. Galectin-3 inhibition sensitizes human renal cell carcinoma cells to arsenic trioxide treatment. Cancer Biol Ther. 2013; 14:897-906.

34. Gao X, Zhi Y, Zhang T. et al. Analysis of the neutral polysaccharide fraction of MCP and its inhibitory activity on galectin-3. Glycoconj J. 2012; 29:159-165.

35. Schnekenburger $M$, Dicato $M$, Diederich $M$. Plant-derived epigenetic modulators for cancer treatment and prevention. Biotechnol Adv. 2014; 32:1123-1132.

36. Kasala ER, Bodduluru LN, Madana RM. et al. Chemopreventive and therapeutic potential of chrysin in cancer: mechanistic perspectives. Toxicol Lett. 2015; 233:214- 225.

37. Abdel Shakor AB, Atia M, Alshehri AS. et al. Ceramide generation during curcumin-induced apoptosis is controlled by crosstalk among Bcl-2, Bcl-xL, caspases and glutathione. Cell Signal. 2015; 27:2220-2230.

38. Hikita H, Kodama T, Tanaka S. et al. Activation of the Mitochondrial Apoptotic Pathway Produces Reactive Oxygen Species and Oxidative Damage in Hepatocytes That Contribute to Liver Tumorigenesis. Cancer Prev Res (Phila). 2015; 8:693-701.

39. Jaiswal PK, Goel A, Mittal RD. Survivin: A molecular biomarker in cancer. Indian J Med Res. 2015; 141:389-397. 